\title{
A short hand of prime number distribution
}

\author{
Vinoo Cameron M.D \\ Hope research, Athens, Wisconsin, USA \\ E-mail: Hope9900@frontier.com
}

\begin{abstract}
This is a short paper to demonstrate how complacent scientists and mathematicians have been and how complacent the mysteries of the sciences are (actually there are no mysteries, the almighty has made mathematics and the sciences in our image) .This is simple mathematics, including the mathematics of the unified theorem that follows this paper, that mathematicians have botched for 500 years. This is also made possible by a unique prime number sieve that is continuum at 6 and 1:3, the denOtter-Hope research continuous sieve for prime numbers, the most accurate prime number sieve. Whilst the discovery of large prime number does nothing for the understanding of prime numbers, the short hand does. We have presented a short series and if so called mathematicians cannot extend the series mathematically, they should join a historical line of western mathematicians that convoluted the reality of mathematics on prime numbers for 500 years.
\end{abstract}

Keywords: Prime number distribution; failure of current mathematics; big Prime numbers.

\section{Introduction}

This is by its published manuscript, and does not need a 100 days of review and refereeing, it is simple , it is clear , it is straight forward, it is what is called mathematics .Its function is curved, called Chan function by us , to honor the Chinese contribution by Dr Hong Ma, editor JAS. It uses the simple logical notion of two alternating cords of prime numbers, and the simple notion that ascension in space is by divergence and by convergence, that adds up to the number 2. Midline is also at +2 . The complex mathematics that proves two spiral cords is presented in an upcoming Manuscript.

The author has recently published papers as shown under references, and one manuscript is shortly due on the spiral sets of prime numbers. This short paper is scientific Diaspora to those Scientists in the world, who are astute enough to understand the different beat of the primordial mathematics, and not the usual mantra of elite science, which has been askew for 500 years. Please Review the 100 page article in the Rutherford Journal of New Zealand about "hunting prime numbers". We have proven that the quarry is at our feet and to painfully note the massive historical convolution about a simple matter of Prime numbers in western mathematics. Current mathematicians should be ashamed.

\section{Mathematics}

This following is by infinite two spiral cords (every other Prime number) that form the basic distribution of prime numbers, the author will give only a short example, and I believe the mathematicians are capable of figuring out the rest, because it is simple. It also confirms a correct sieve. Kindly review the published references, listed at the end.

Roll of Prime numbers: simple arithmetic, based on simple logic!!

$11,1319,23,29,31,41,43,47,53,59 \ldots \quad$ The two rational cords from this roll are

A. $13,19,29,37,43,53,61 \ldots$

B. $11,17,23,31,41,47,59 \ldots$ 


\subsection{The long hand}

A. $(19 * 13)+(19 * 16)=29 * 19 \ldots(29 * 19)+(29 * \mathbf{1 8})=(29 * 37) \ldots(29 * 37)+.(37 * \mathbf{1 4})=(43 * 53)>$ infinite

B. $(17 * 11)+(17 * \mathbf{1 2})=(17 * 23) \ldots(17 * 23)+(23 * 14)=(23 * 31) \ldots(23 * 31)+(31 * \mathbf{1 8})$

$=(31 * 41) \ldots 31 * 41+(41 * 16)=41 * 47>>$ Infinite

\subsection{The short hand}

A. $13+\mathbf{1 6}=29 ; 19+\mathbf{1 8}=37 ; 29+\mathbf{1 4}=43 ; 37+\mathbf{1 6}=53>$.infinite

B. $11+\mathbf{1 2}=23 \ldots 17+\mathbf{1 4}=31 \ldots 23+\mathbf{1 8}=41 \ldots 16+31=47>$ infinite

Although the full resolution is by published papers in this very journal and JAS, the following is the full clear proof of the quadratic base of the prime number spirals.

$$
\begin{gathered}
23=14 \mathrm{hl} \\
19=16 \mathrm{hl} \\
\frac{23}{6}-\frac{19}{6}=\frac{2}{3} \\
\frac{16}{6}-\frac{14}{6}=\frac{1}{3} \\
\frac{23}{6}+\frac{19}{6}=7 \\
\frac{14}{6}+\frac{16}{6}=5 \\
\frac{12}{6}+\frac{14}{6}=4.333333333 \\
\frac{12}{6}+\frac{16}{6}=4.666666666 \\
4.66666666666+4.333333333333=9 \\
4.6666666666666-4.3333333333333=\frac{1}{3}
\end{gathered}
$$

\section{Conclusion}

This paper makes for more understanding of mathematics, than the convolution of the current western mathematics George Riemann et al, and the biggest prime number at the University of Missouri USA!, and 500 years of intrigue and mysteries about prime numbers. The author is afraid that the western mathematics has led the rest of the world astray by their Spartan attitudes of the last 500 years that has convoluted mathematics. A big hat does not make for a big mathematics. Mathematics begins and ends at the number 1

\section{Acknowledgements}

1. My Lord Jesus Christ, by his special grace to me, specially the teaching of humility and clarity that is lacking in current western mathematics.

2. Dr. Hong Ma editor of Journal of American science who was humble / decent to me and understood creativity in Science, he is instrumental in giving us confidence.

3. IJAMR, and Professor B. Batiha, for a very decent understanding of the obtuse mathematics that he has been presented with, by this way ward mathematician. 


\section{References}

[1] Cameron .V, The disproof and fall of the Riemann's hypothesis by quadratic base: The correct variable distribution of prime numbers by the clear mathematics of the half-line values ("Chan function") of prime numbers, International Journal of Applied Mathematical Research, 2 (1) (2013) 103-110.

[2] Cameron V, den Otter T. Prime numbers 2012. Jam Sci 2012; 8(7):329-334]. (ISSN: 1545-1003), http://www.jofamericanscience.org.

[3] Cameron V, Prime number Coordinates and calculus J Am Sci, 2012; 8(10):9-10]. (ISSN: 1545-1003).http://www.jofamericanscience.org.

[4] Prime number19, Vedic Zero and the fall of western mathematics by theorem. International journal of applied mathematical research 2(1) (2013)111-115. 